\title{
FRONTERA: ¿MURO DIVISORIO O TEIDO DE RELACIONES?
}

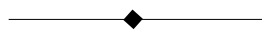

\section{RESUMEN}

El propósito de este artículo es presentar una nueva mirada a los hechos de nuestro mundo; es decir, aportar elementos para ver la realidad desde otro nivel de conciencia o, dicho de otro modo, permitir la llegada de un nuevo paradigma que cambie muchos aspectos de nuestra comprensión de la verdad.

Dividiremos esta reflexión en dos partes: en la primera se analizará la frontera desde el punto de vista sociológico e histórico - descrita como externa, fundada a partir del antiguo modelo reduccionista y fragmentario de la ciencia - para después, en una segunda parte, hacerlo desde la óptica psicológica - vista como interna, sustentada en el modelo integrador y holístico que nos propone la ciencia de hoy-, logrando así una visión de la totalidad de dicho concepto.

\section{A BSTRACT}

The objective of this article is to take a new look to the facts of our world; it means, to offer elements to observe the reality from another level of awareness, or to admit the arrival of a new paradigm that changes many aspects of our understanding of the truth.

We will divide this reflection in two parts: the first will analyze the frontier from the sociological and historical point of view, described as external, founded on the old model of science both reducing and fragmentary. Then, in a second part, it will seen from the psychological vision, internal, sustained on an integrating and holistic model proposed by today's science, thus obtaining a vision of the totality of said concept.

* Investigadora del Instituto de Investigaciones Sociales de la UABC. Correo electrónico: ndiesbach@uabc.mx 
INTRODUCCIÓN

La frontera le fascinaba

Julien Grack

La frontera entre México y Estados Unidos es una de las más largas del mundo: son más de tres mil kilómetros que unen culturas, razas y lenguas de diferente origen. Este solo hecho conlleva vivenciar situaciones sin paralelo en el mundo; cruzarla habitualmente trae otro tipo de experiencias que no cualquier migrante puede experimentar $y$, sobre todo, en ella se es testigo de importantes acontecimientos de trascendencia no sólo para los países involucrados, sino para el resto del orbe, de ahí que la llamada "línea" sea un lugar sui generis.

Este espacio geográfico denominado frontera, abre la pauta para la reflexión acerca de la construcción del concepto no sólo en lo físico sino en el interior decada uno denosotros, es decir, cómo el ser humano experimenta fronteras en su propio ser y las refleja en el exterior.

En este artículo se concentra la atención en el concepto frontera. Para el desarrollo del tema, en la primera parte se describe a ésta desde una óptica externa, fundada en el antiguo modelo de ciencia, con una perspectiva reduccionista y fragmentaria. En la segunda se analiza el término frontera interna, concepto sustentado sobre el modelo integrador y holístico que plantea la ciencia física de hoy; en esta parte se propone ampliar su acepción y se sugieren nuevas rutas para leer su sentido y la importancia que tiene para una mejor convivencia entre quienes habitamos en el planeta. De hecho, decir "frontera" hoy sugiere temas muy variados, por ejemplo, las relaciones internacionales con sus aspectos cruciales, tales como: migración, comercio, movimientos de capital, contrabando, narcotráfico, conflictos diplomáticos, etcétera, que se refieren al nivel social y geopolítico de estos Estados. Sin embargo, la concepción de frontera es más amplia, como se verá más adelante.

Usualmente, el término frontera - con nuestro cuadro mental tradicional basado en la fragmentación- insinúa separación, demarcación o hasta obstáculo; pocas veces, encuentro, reunión, 
enriquecimiento mutuo y aún amistad. Este concepto se utiliza sobre todo en la esfera de lo físico, penetrando en todas las percepciones de la vida cotidiana, lo que determina la esfera mental, emocional e incluso la humanista. Prueba evidente de ello es el dualismo entre mente y cuerpo, la separación tajante entre el ser humano y su entorno, entre pueblos y razas distintas, en la exclusión y la discriminación contra lo diferente.

Una concepción que implica transformación permanente, mudanza histórica y hasta revolución científica, es la de paradigma, concepto introducido por el historiador Thomas Kuhn. A partir de la publicación de su obra La estructura de las revoluciones científicas (1971), se conformó la noción de que las ópticas científicas corresponden a momentos e intereses históricos diferentes, a realidades surgidas de contextos geográficos y sociales de diversa índole. Asimismo, se demostró que el paradigma científico vigente surgió en un momento en el que la sociedad europea se debatía entre la desaparición del oscurantismo y los albores de un nuevo periodo científico, cuyos inicios fueron dados por los descubrimientos de N ewton, Kepler y Galileo.

Sin embargo, dados los cambios socio-históricos, es necesario transformar la perspectiva científica, ya que el mundo actual requiere de un nuevo paradigma que le permita integrar, comprender, explicar y resolver los retos que tiene la humanidad en estos tiempos.

A hora bien, la circunstancia especial de estar ubicados geográficamente en una zona limítrofe, implica que al realizar estudios sobreel concepto de frontera se deba subrayar el papel de este nuevo paradigma en la visión para analizar esta realidad, ya que permite una noción de apertura, amplitud, integración e interdisciplinariedad, típica del enfoque holístico. Así, se puede considerar a la frontera como el límite existente entre diversos elementos o personas y, además, agregar a esta consideración, la distinción entre "externas" - abordadas como líneas visibles y sociológicas- e "internas" - tratadas como invisibles, psicológicas, latentes en la forma de ordenación de la realidad-.

De esta manera, invito al lector a adentrarse en la reflexión de este concepto, analizar su construcción tanto externa como interna, y 
comenzar a abrir sus sentidos hacia una nueva percepción como propuesta para un cambio en la visión de la realidad.

\section{DETERMINACIÓN DE MODELO DEL CONCEPTO FRONTERA}

El término frontera se refiere a la existencia de límites, bordes o confines, ${ }^{1}$ pero el ser de estos bordes fronterizos dibuja también, además de separación o delimitación total, la aparición de identidades culturales tanto disímiles como recurrentes.

Los casos de separación son variados: en la antigüedad hubo muros como protección de las ciudades en contra de los posibles enemigos, por ejemplo: Jerusalén y Roma; en la edad media, existieron las ciudades fortificadas; Ios ciudadanos de Londres y París son otra muestra, pues construyeron y reconstruyeron murallas para salvaguardar su libertad; de la misma manera fue levantada la Gran Muralla China, con una extensión de $10000 \mathrm{Km}$.

El caso de la frontera entre México y Estados Unidos representa uno de los ejemplos de recurrencia. Es un lugar que ve nacer una identidad cultural propia de los habitantes tanto del sur de Estados Unidos como del norte de México. Y es que la frontera representa también la existencia de redes de interrelación y no sólo de aislamiento o separación.

Pero, ¿es la frontera una creación natural o una convención social? Se ha debatido mucho respecto a esta cuestión, sin embargo, han sido fundamentalmente dos modelos de pensamiento que han tenido a bien el enfrentarse y complementarse a un tiempo para obtener el discernimiento total de lo que las fronteras son y representan para el ser humano. Los límites son por todos conocidos a partir del paradigma cartesiano y mecanicista que nos rige actualmente. En dicho modelo, los bordes representan al go físico y tangible. En cambio, la existencia de un nuevo paradigma, bajo otros puntos de referencia, nos da una concepción renovada de las fronteras

${ }^{1}$ Vid. Diccionario de la lengua española, Porrúa, México, p. 340. 
y los límites que, desde esta óptica, perecieran más suaves y menos contrastantes.

Sin embargo, antes de entrar al análisis del término en sí, es necesario dar un recorrido por los principales puntos de referencia que darán forma a este artículo. Para ello, es importante revisar al gunos tópicos esenciales en la construcción del marco teórico que precede a nuestro análisis.

Un paradigma es un marco de referencia que contribuye a explicar, enfocar y comprender aspectos de la real idad que se desea estudiar. Es posible decir, entonces, que un paradigma constituye una visión del mundo y la base de todo un sistema de valores, pues no debe olvidarse que el punto de vista que rige la manera de pensar del individuo, determina todos los aspectos de su realidad viviente.

El filósofo e historiador Thomas Kuhn estableció la más importante aportación para nuestro estudio en este tópico. Él se refiere al paradigma como una "constelación de creencias, valores y técnicas compartidos por una comunidad científica determinada" (Kuhn, 1971:3).

Un paradigma se vuelve operante entre una comunidad de científicos por el éxito que tiene en la competencia con los demás para la resolución de problemas concretos. Así que, cuando este marco de referencia se ha convertido en una manera aceptada por la mayoría de esa comunidad, se vuelve la forma obligatoria de enfocar las interrogantes y su solución. Entonces el modelo se convierte en lo que Kuhn Ilama la ciencia normal, volviéndose inflexible para nuevas ideas y aportaciones que cambien dicho enfoque.

Debido a que el modelo de pensamiento predominante admite únicamente como válidos aquellos problemas que pueda resolver, entonces considera como subversivos los planteamientos que son imposibles de ser resueltos. Esto representa una evidente limitación cuando un científico pretende ampliar la óptica de interpretación de su modelo.

Cuando un paradigma es superado, se produce lo que Kuhn Ilama las revoluciones científicas, que son "aquellos episodios de desarrollo no acumulativo en que un antiguo paradigma es reemplazado, completamente o en parte, por otro nuevo eincompatible" (Kuhn, 1971:149). 
Como se dijo, un paradigma influye también en la manera de percibir, pensar y construir al mundo, por lo que al presentarse esta revolución científica, cambia también la concepción del mundo que se tenía. Estas transformaciones representan una trascendental variación en la construcción de los problemas a resolver y en las soluciones a proporcionar. Por lo regular, estas innovaciones comienzan a darse en pequeños grupos de personas que se muestran inconformes con los resultados obtenidos por la manera de ver la realidad. Sin embargo, la apreciación desde otro paradigma no supone el rechazo del anterior; se toma lo que es útil para el nuevo enfoque, y lo demás es susceptible de sufrir cambios sustanciales que se adapten a la nueva forma de comprensión de la realidad.

Ahora bien, es posible determinar la presencia de dos modelos fundamentales en el pensamiento moderno que permiten tener una manera de hallar la explicación a los fenómenos que ocurren - tanto sociales como naturales-. Estos dos model os son el paradigma mecanicista-cartesiano, y el llamado holista-integrador, de los cuales se da un ligero esbozo a continuación.

Durante la edad media, la manera de hacer ciencia tomaba un enfoque religioso que era imposible traspasar. Se tenía “la visión del universo como algo orgánico, vivo y espiritual" (Capra, 1998:56). Sin embargo, durante los siglos XVI y XVII, el mundo fue testigo de una revolución científica importante.

Con la aparición de las teorías de Copérnico, Galileo y Newton, la visión del mundo cambió a otra en la que se le apreciaba como una máquina funcional. La concepción de la realidad fue trastocada, y a partir de ese momento dio inicio la época de la llamada revolución científica. En esta revolución, la sociedad pasó a ser un ente perfectamente funcional y lineal, donde el progreso de la humanidad era medido por su alcance tecnológico y de conquista de la naturaleza.

Los científicos de la época -Galileo, N ewton, Kepler- se dedicaron entonces a encajonar la realidad. Comenzaron a hacer leyes y métodos que les permitían estudiar las cosas que estuvieran al alcance de su marco de referencia y su percepción; la naturaleza y la sociedad tuvieron que ser explicadas y entendidas matemáticamente; exduyeron entonces todo aquello que no era tangible y no representaba 
evidencia física y comprobable. Así pues, la visión de estos científicos era cartesiana y mecanicista. Lo primero, por la concepción de Descartes, consistente en "dividir los pensamientos en cuantas partes sea posible y luego disponerlos según un orden lógico" (Capra, 1998:62), y lo segundo, por la noción de sistema mecánico susceptible de interpretarse a través de datos concretos proporcionados por una realidad palpable.

Surgió entonces el siglo de las luces, época en que la bandera del progreso y, por ende, el desarrollo lineal de la sociedad, tuvieron pleno auge. Tiempo después -en el siglo XVIII- aparecieron los pensadores que trasladaron este paradigma a las cuestiones sociales, al grado de que autores como Auguste Comte, por ejemplo, vieron en la física el sustento a su visión de lo social, naciendo así la física social.

El modelo mecanicista cartesiano concibe al mundo como ente explotabley aprovechable para el beneficio humano. Así, crisis como la destrucción de la naturaleza en pro de su conquista, la discriminación entre humanos de distintas razas o credos, entre otras, son cosa común en el mundo de hoy, caracterizado por la falta de valores y de visión planificadora e integral a largo plazo, derivada del paradigma que nos rige hasta estos días.

Esta situación se manifestó con mayor agudeza a partir del siglo XX. Algunos científicos - entreellos Einstein y Bohr - se dieron cuenta de que este paradigma ya no era acorde al tiempo histórico y al desarrollo dela sociedad, iniciando así un periodo debúsqueda, donde predomina el replanteamiento de problemas, el caos conceptual, la construcción de nuevas metodologías y la emisión de respuestas.

Las situaciones de crisis económica, humana, social y ecológica han Ilegado a un punto que denota la existencia del paradigma mecanicista como insuficiente. El progreso lineal visto desdela óptica de conquista de la naturaleza y entre los grupos humanos para beneficio de quienes detentan el poder, ha trastornado la percepción que se tiene de los problemas que afectan a la humanidad y sus posibles soluciones.

Es a principios del siglo XX cuando los científicos -entre ellos Albert Einstein en sus investigadiones acerca de la relatividad, publicadas en 
1905 - comienzan a ver y construir la realidad desde otra óptica. La perciben como un conjunto de elementos interrelacionados e interdependientes entre sí, superando al pensamiento cartesiano. Así, ellos argumentan que la totalidad influye en la construcción de la misma. Lo que se requiere, subraya el físico moderno Fritjof Capra en obras como 0 Tao da Física (1983) o El punto crucial (1998), es una visión innovadora que nos permita apreciar el mundo desde otra perspectiva, donde veamos un todo integrado y donde contemos con un panorama más amplio de la realidad y el entorno. Afirma, además, que nuestra percepción de la realidad es limitada, ya que no nos atrevemos a ver más allá de lo que podemos comprender.

Por otra parte, la percepción construida bajo el marco de referencia del nuevo paradigma holista - el segundo modelo al que hicimos referencia anteriormente - toma en cuenta, además, valores como la cooperación, las emociones, la estética, la ecología, entre otros, razón por lo cual se vuelve más humanístico eintegrador que el mecanicista. Es un pensamiento multicausal. No sólo cree en lo que ve, sino que también toma en cuenta la subjetividad del observador. No cree en la construcción aséptica de lo objetivo, sino que considera la determinación del filtro del investigador, calificándolo de observador participante y, por ende, que influye en dicha construcción.

Esta corriente de pensamiento propone una integración de elementos interrelacionados para la construcción de una realidad donde la ciencia y el espíritu humanista y de cooperación se unan para dar una explicación que nos acerque a la verdad.

Tomando como base los dos model os de pensamiento antes descritos, a continuación se realiza el análisis que cada uno de ellos tiene sobre el concepto de frontera. En ambos se considera el caso de la frontera entre México y Estados Unidos, tanto a nivel externo - la frontera física, palpable entre ambos países-, como interno - tomando en cuenta las múltiples relaciones de cooperación y convivencia entre los habitantes de la zona-. La cercanía con el punto mencionado, así como su importancia a nivel mundial, determinan la presencia de éste en el análisis y constitución del estudio aquí descrito. 
FRONTERAS EXTERNAS

FRONTERA COMO MURO DE DIVISIÓN

La frontera es una relación que margina y presupone algún dolor, algún rencor vivo y operante... Antonio Paoli

A ntes de ser una realidad, los Estados U nidos fueron para mí una imagen. $N$ ada extrañó a eso: desde nuestra infancia, los mexicanos, vemos a este país como el otro. Un otro inseparable de nosotros mismos y que, al mismo tiempo, es radicalmente, esencialmente extranjero.

Octavio Paz

Se hablaba ya que el modelo cartesiano de pensamiento únicamente acepta lo palpable, visible y medible como válido. El hecho de romper con el modelo medieval de concepción teológica, marca la pauta para dividir a la humanidad en dos partes: aquéllos que seguían creyendo en la importancia de Dios como ente fundamental en la realidad, y los otros, que se atuvieron completamente al método científico para llegar a la verdad.

La consecuencia de la visión adquirida por el antiguo paradigma se refleja en el mundo cuando encontramos más separación que integración; más división que relación entre razas, naciones, religiones, sexos, etcétera. Las divisiones norte/ sur, el enfrentamiento entre humanos, la creación de fronteras limítrofes, son manifestaciones o invenciones de este pensamiento divisionista de este tiempo. El término frontera en esta visión toma un matiz fundamentalmente físico y geográfico, y encuentra su significación en palabras como límite, borde o diferencia.

Con esta concepción, nace también la noción de Estados-nación y su consecuente búsqueda de la soberanía en independencia cultural, política y social. Surgen, así, las luchas por la conquista de territorio y de grupos humanos para el desarrollo lineal y progresivo de los países. Es ahí cuando se establecen los límites que separan a los Estados y nacen las fronteras entre las naciones. 
El geógrafo francés Michel Foucher, en su libro Fronts et Frontières (1988), nos dice que, de manera general, las fronteras han sido el resultado de las guerras. En lo que concierne a América Latina, cerca de $27 \%$ de la longitud de sus fronteras - $11860 \mathrm{kms}-$ ha surgido de esta circunstancia, ya sea directamente, por el hecho de la victoria de una de las partes, o indirectamente, como producto de tentativas militares indecisas. Si añadimos el límite Ecuador-Perú, siempre en litigio y objeto de un conflicto armado en 1981, la totalidad se acerca a $13000 \mathrm{~km}$, es decir, 30\% de todas las fronteras de la zona (Foucher, 1988:116).

CONSTRUCCIÓN POLÍTICA Y SOCIAL DE LA FRONTERA NORTE DE MÉXICO

El caso de la frontera entre M éxico y Estados Unidos representa más que el límite entre estos dos países. Es la más tangible muestra de la separación y la oposición de intereses entre el mundo occidental y la cultura latinoamericana, con sus respectivas formaciones sociales y distintos niveles de desarrollo.

Existen tantas fronteras geopolíticas en el mundo como países en él; sin embargo, pocas han sido tan hostiles y agresivas como la frontera norte de México. Es tan evidente y real esta "línea", que se intenta frenar el incesante flujo migratorio hacia Estados Unidos con una malla de alambre y placas de acero, formando una representación física y violenta de la separación entre ambas naciones.

Desde mediados de la década de los cuarenta y hasta finales de la década de los ochenta del siglo XX, se tuvo un ejemplo similar en la frontera que dividió a Alemania en dos partes. En el muro de Berlín, las violaciones a los derechos humanos y las garantías individuales eran cosa de todos los días. En el borde norte de México suceden de manera cotidiana los mismos actos de represión, los mismos peligros de muerte, el mismo trato inhumano. $Y$, aunque parezca incréble, es muy similar el trato entre compatriotas mexicanos al que se daban los alemanes de hace treinta o cuarenta años.

Más allá de su imposición materializada, el muro de la frontera norte de México representa la acumulación de violencia, frustración, 
luchas fraticidas y miedos al "otro". Es la imagen concreta de lo que hemos generado en el pasado y que, en la actualidad, forma una barrera explosiva inhumana y cruel que es fruto -en ambos lados de la línea- del miedo a no poseer, a ser despreciado, aprensión al extranjero, a lo desconocido; temor fundado en la inseguridad de no saber del futuro, del presente, de quién soy y adónde voy. Con todo ello, esta frontera no es realmente invencible. Por sus condiciones físicas, es franqueable y violentada muchas veces por las personas que tienen interés por cruzar al lado estadounidense. La "línea" no es cerrada, sino representa una enorme bisectriz en medio del vasto mar de cobertura de influencias, jugando en ambas direcciones.

Aun cuando las cosas parecieran estar controladas, muchas veces Estados Unidos rompe sus propias reglas con tal de que se permita la entrada a inmigrantes ilegales por sus fronteras, con el fin de contribuir al desarrollo de la economía. Ésta es una actividad común, ya que les permite tener mano de obra barata a la que no le incomode hacer toda clase de trabajos. Estas incursiones ya antiguas, se combinan con un proyecto de inspiración originalmente geoeconómico, que consiste en reforzar las bases del poder de los Estados Unidos, apoyándose sobre los potenciales más cercanos en el plano geográfico.

En suma, si acentuáramos la integración de los tres países de N orteamérica en una entidad, resultarían: 21 millones de $\mathrm{km}^{2}$, unos 400 millones de habitantes, y más de 4700 mil millones del producto nacional bruto -E.U: 4 200; Canadá: 360; México: 160-, (datos de 1986; Foucher, 1988:368). Cuestiones como el Tratado de Libre Comercio de A mérica del Norte (TLCAN) son prueba tangible de un plan geopolítico de dominio y conquista que tiene Estados Unidos hacia los demás países, en especial aquéllos que considera inferiores a él.

Y precisamente, Foucher aporta datos significativos a esta cuestión, donde puede verse que la represión no se hace esperar: el Congreso de Estados Unidos aumenta cada año el presupuesto de la ofcina de Inmigración y Naturalización (INS, por sus siglas en inglés), encargada de la vigilancia de los $3250 \mathrm{~km}$ de frontera con México. Este tipo de medidas fueron tomadas a partir de 1982, 
cuando los políticos estadounidenses comenzaron a atribuir el desempleo, las dificultades económicas y la delincuencia a la inmigración hispana. Este pensamiento se resume en la frase del abogado W.F. Smith, dicha en este mismo año: "Hemos perdido el control de nuestras fronteras" (Foucher, 1988:379).

A partir de entonces, dice Foucher, ciertas voces se elevaron en pro de la edificación de un muro o una barrera metálica continua en los sectores de cruces clandestinos. En realidad, la frontera había quedado un largo tiempo abierta, y su cierre no es muy antiguo. La Patrulla Fronteriza se creó en 1924, en un periodo de optimismo económico, marcado por un refuerzo del proteccionismo aduanero, una ola xenofóbica, ilustrada por las actividades del Ku Klux Klan, y una limitación del conjunto de la inmigración. Sin embargo, las prohibiciones generalizadas favorecieron la transferencia de actividades ilícitas en territorio de la unión americana hacia las ciudades mexicanas fronterizas, lo que marcó el comienzo de su florecimiento, así como también su mala fama, la cual persiste en la imagen que los estadounidenses conservadores tienen del norte de México: lugares reputados como sede del «pecado», bajo todas sus formas - prostitución, juegos de azar, al cohol, droga, contrabando, carreras de caballos-, visión que muy a menudo se extiendea México en su conjunto (Foucher, 1988:380).

Foucher afirma que esta alternancia de apertura y restricción ha contribuido a la formación de una verdadera región mexicana fronteriza al "otro lado", o más bien, a la formación de una serie de polos urbanos, de ciudades gemelas (twin cities) que agrupan hoy una población mexicana importante sobre una larga banda de 20 a 50 millas adentro de los estados del sur de los Estados Unidos. Esto forma un espacio transfronterizo original de verdad, que no es sólo un lugar transitorio y de espera para nuevos inmigrantes, sino es parte, de manera funcional, de las áreas metropolitanas estadounidenses.

En su estudio socioeconómico La frontera M éxico-Estados U nidos (1980), Raúl Fernández subraya en particular el concepto de "región fronteriza", como una entidad separada que se extiende al norte y al sur de la línea límite internacional, y considera esta área como única por el hecho de que implica un territorio más vasto que 
la simple línea de borde, única también por su heterogeneidad y diversidad, al considerar sus aspectos económicos, lingüísticos y culturales (Fernández, 1980:169-170). Para este mismo autor, lo que hace que la frontera entre los Estados Unidos y México sea "única" es, en primer lugar, por el hecho del desarrollo de estos centros poblacionales Ilamados "ciudades fronterizas", que se extienden desde el golfo de México hasta el océano Pacífico, y en segundo lugar, porque esta denominación en general no ha sido aplicada a los centros poblacionales de la frontera americano-canadiense, la cual se conoce como "territorio limítrofe" (Fernández, 1980:11).

Así, la palabra "fronteriza" y en especial la expresión "ciudad fronteriza", tienen connotaciones - según este autor- "negativas" que implican condiciones de inestabilidad y hostilidad, por el hecho de no tener otro propósito que el de establecerse en puntos de cruce. Entonces, estas ciudades desafían las leyes de la teoría de localización económico-geográfica, y deben su supervivencia a la existencia de dicha condición limítrofe (Fernández, 1980:12).

Las ciudades de la frontera, aceptando su vulnerabilidad, han aprendido -en la opinión de Alan Riding en su obra V ecinos distantes (1985:344-345) - a vivir de su ingenio, ajustándose a los gustos cambiantes y a los climas económicos. "Al igual que las ciudades fronterizas de todo el mundo, éstas buscan leyes laxas y utilidades rápidas".

Se calculan alrededor de cuarenta puertos terrestres a lo largo de la frontera México-Estados Unidos, de los cuales siete se encuentran en California. Se estima que el número de "entradas" desde México se acerca al centenar de millones por año a lo largo de toda la frontera, lo cual nos da una idea de una serie de regiones urbanas transfronterizas (datos de Foucher, 1988:381).

Es palpable para los habitantes de la zona fronteriza, que los lugares de la frontera más frecuentados forman hoy una verdadera red electrónica de protección. Este dispositivo de vigilancia - de eficacia creciente- empleado con fines civiles, es único en el mundo. De hecho, el empleo de técnicas de origen militar que fueron "civilizadas", evitaron una militarización de la frontera. Sin embargo, la violencia es innegable: golpizas, violaciones, desapariciones y hasta de asesinatos son objeto los aspirantes a ilegales a manos de 
los "guardianes de la frontera", quienes con frecuencia los tratan como si fueran criminales.

CONSTRUCCIÓN GEOPOLÍtiCA y ECONÓMICA de LA FRONTERA NORTE DE MÉXICO

En opinión de Foucher, la frontera méxico-americana es un caso único en el mundo como región industrial distribuida a lo largo de la línea limítrofe, fundada sobre la explotación metódica de una doble discontinuidad: al sur, una numerosa mano de obra migratoria en espera de un empleo y un salario; al norte, el primer mercado del mundo, sometido a una gran competencia extranjera. En una palabra: una situación que un economista frío calificaría de "complementariedad estructural" (Foucher, 1988:378).

Esta situación de región industrial fue utilizada desde 1965 con el fin de crear fuentes de trabajo para anclar a los migrantes en México mismo y, además, para obtener una mano de obra aproximadamente siete veces menos cara que en Estados Unidos. Las empresas estadounidenses, a través de las maquiladoras fronterizas, tienen así un modo de producción off-shore y, al mismo tiempo, a las puertas del mercado, como también protegido de la competencia internacional, sobre todo asiática, en una serie de ciclos de producción, en especial lo que es electrónica, informática, juguetería, etcétera (Foucher, 1988). El analista afirma que en ambos lados de la frontera se teme - lo que ya sucede - una transición del norte de México a la subcontratación, por la formación, sobre el territorio mexicano, de enclaves estadounidenses extraterritorial es $u$ off-border, como comúnmente se les Ilama. A demás, otra cuestión que beneficia a Estados Unidos es que se estima que la cuarta parte del salario de los obreros se gasta en el país del norte, en las ciudades situadas "al otro lado" (ver Foucher, 1988).

La subcontratación fronteriza se da también de México hasta Estados Unidos, y sigue penetrando a veces muy dentro de este último territorio: unos dos millones de "indocumentados" se encuentran en la mitad occidental de este país, al oeste del meridiano de Chicago, en donde constituyen la mano de obra barata en diversos 
talleres y servicios. Se añaden a ellos alrededor de un millón de trabajadores mexicanos que trabajaron en un programa especial Ilamado "Special Agriculture Workers" (SAW), quienes, durante 6 meses al año, levantaban la cosecha en unas 52000 empresas agrícolas del suroeste árido (Foucher, 1988:379).

La expresión de Alan Riding corresponde bien a la vivencia de los mexicanos migrantes ilegales. Si a los ojos de algunos mexicanos, los Estados Unidos es visto como un país de salvación para la sobrevivencia, para muchos otros es percibido como amenazador. La percepción de amenaza nace de la conciencia de asimetría entre los dos Estados y de la capacidad de influencia desmesurada de los Estados Unidos sobre la economía y la situación política interna del Estado mexicano (Riding, 1988:376).

La frontera entre los Estados Unidos y México, subraya Fernández, es un ejemplo contemporáneo único en cuanto al contraste existente entre naciones ricas y pobres 0 , como habitualmente se denomina, entre naciones "desarrolladas" y "subdesarrolladas". La colindancia de estos dos países hace resaltar los tipos de lazos que se establecen entre naciones desiguales a nivel socioeconómico, lo cual provoca la continua saturación de inmigrantes mexicanos en los estados del suroeste de Estados Unidos (Fernández, 1980:12).

Michel Foucher subraya que México forma parte de un sistema geopolítico singular: es cierto que, por un lado, los Estados Unidos ejercen un completo dominio sobre dicho sistema, sin embargo, es profundamente heterogéneo y contradictorio porque, según su análisis, mientras se vea como una línea de discontinuidad entre dos formaciones sociales distintas y aceptadas como tales, la frontera será fría y de buena vecindad, "de manera que la región del río Grande es una en la que los norteamericanos deben aceptar un límite a su poder de influencia, quizás por sus propios intereses" (Foucher, 1988:389).

Fernández, por su lado, se pregunta si es posible referirse a la región fronteriza como nación o colonia. Considera que ésta no debe ser definida como área homogénea culturalmente, ni como nación, puesto que las bases para poder hablar de un área con un grado de cohesión son dobles: geográficas y económicas. Por lo que se refiere a lo geográfico, existe a lo largo de toda la frontera una cierta 
homogeneidad destinada a influir en el carácter y en los rasgos de cualquier desarrollo humano (Fernández, 1980:174-176). Asimismo, Fernández considera que esta base geográfica natural es fundamento sustancial de las fuerzas y relaciones económicas de la región. En cuanto a las bases financieras, ellas radican — subraya el autor - en la desigualdad, el desarrollo dispar y la dominación. Así, "hablar de una unidad económica regional fronteriza (...) es hablar de la continuación del statu quo en los Estados Unidos y México" (Fernández, 1980:177).

Gracias a la visión proporcionada por estos autores, es posible afirmar que la frontera norte de México, a pesar de ser históricamente una zona de intensos intercambios humanos, culturales y económicos, es, a la vez - por esta misma situación-, una zona que oscila entre la apertura y el cierre, y representa, además, un modelo de la frontera/ separación, protección/ aislamiento, el cual se construye dentro de un contexto caracterizado por una polarización de las relaciones binacionales de índole dominado/ dominante, visión proporcionada claramente por el modelo mecanicista cartesiano.

\section{FRONTERAS INTERNAS}

FRONTERA COMO TEJIDO DE RELACIONES

Temo que la verdadera frontera la trae uno adentro.

Carlos Fuentes

La teoría cuántica nos obliga a ver el universo, no como una colección de objetos físicos, sino más bien como una red compleja de relaciones entre las distintas partes de un todo unificado.

Fritjof Capra

Si encuentro a alguien capaz de ver las cosas en su unidad y en su multiplicidad, ése es el hombre al que yo busco como a un Dios.

Platón

La visión ecológica se basa en el principio de interrelación e interdependencia de los elementos que conforman la realidad. A partir de 
este supuesto, se construye una nueva manera de percibirla, de descubrir las redes que interconectan a los múltiples fenómenos y procesos que acontecen en la cotidianidad. Según esta visión, si las fronteras externas existen, las hay también en nuestro interior. Esto tiene una explicación sencilla: Ios pensadores de esta nueva corriente tienen la convicción de que en los seres humanos lo "interior" se refleja al exterior, así que, por analogía, si existen barreras en nuestro "adentro", éstas se manifestarán "afuera".

CONSTRUCCIÓN PSICOLÓGICA Y HUMANÍSTICA DEL TÉRMINO FRONTERA

Según la corriente de pensamiento holista y ecológica, existe un proceso básico que subyace a todo el procedimiento para establecer una identidad. Cuando uno responde a la pregunta "¿Quién soy?", sucede algo muy simple: Al describir o explicar quién "es" uno, incluso cuando se limita a percibirlo interiormente, lo que en realidad se está haciendo, es trazar una línea o límite mental que atraviesa en su totalidad el campo de la experiencia, y a todo lo que queda dentro de este límite se percibe como "yo mismo", mientras siente que todo lo que está por fuera del límite queda excluido de él. En otras palabras, la identidad de cada quien depende totalmente del lugar en donde tracemos la línea limítrofe. De modo que al decir "yo", trazamos una demarcación entre lo que somos y lo que no somos. Lo que solemos llamar crisis de identidad se produce cuando uno no puede decidir cómo ni dónde establecer esa línea.

Este enfoque holista de la ciencia se basa en las fronteras interiores que el ser humano experimenta, que vienen a ser todas aquellas fronteras psicológicas y de personalidad que el individuo crea - consciente $o$ inconscientemente- como una forma de protección contra un ambiente hostil; sin embargo, estas líneas no son físicas, sino que derivan de una concepción más profunda de trascendencia.

Ken Wilber, en su obra Conciencia sin fronteras (1988) - que representa la fuente principal de esta parte del ensayo-, afirma que lo más interesante es que la línea divisoria de nuestra identidad (de la misma manera que la frontera física) puede desplazarse, y con 
frecuencia lo hace. Las formas más radicales de cambiar de lugar la línea limítrofe en el ámbito psicológico se dan en las experiencias de la identidad suprema, en las que las personas expanden el límite de su propia identidad hasta incluir la totalidad del universo. Es posible decir que replantea completamente la línea limítrofe, "porque cuando está identificado con el 'todo único y armonioso', ya no hay dentro ni fuera, y por lo tanto no hay dónde trazar la línea" (Wilber, 1988:16). Esto es lo que constituye la percepción sin fronteras que se conoce como la identidad suprema o conciencia de unidad.

Asimismo, Wilber dice que cuando un individuo diseña los límites de su ser, establece al mismo tiempo las batallas internas. Los límites de la identidad de un individuo demarcan qué aspectos del universo deben ser considerados como "uno mismo", y cuáles serán considerados "Io que uno no es". Son diferentes los aspectos del mundo que se le aparecen al individuo como "lo que no soy", lo ajeno, extraño o extranjero. Freud ya lo había señalado: todo extraño parece un enemigo, entonces, cada nivel está potencialmente comprometido en diferentes conflictos con diversos enemigos (Wilber, 1988:24-25).

Este autor se refiere a queel objetivo del psicoanálisis y dela mayoría de las formas de terapia convencional, es remediar la radical escisión entre los aspectos conscientes e inconscientes de la psique, y ayudar a que la persona se ponga en contacto con "la total idad de su mente". Estas terapias orientadas hacia el nivel del ego, apuntan a reunificar a la persona, Ilamada también máscara (tras la que se ocultan los aspectos inaceptables de su ego), y la sombra (que proyecta al exterior estos aspectos), con el fin de crear un ego sano y fuerte.

De la misma manera, la mayoría de las Ilamadas terapias humanistas o transpersonales tienen por meta curar la escisión entre el ego y el cuerpo, "reunir" la psique y el sombra para así revelar el organismo total. Es por eso que a la psicología humanista se le designa como "movimiento de potencial humano". De hecho, al extender la identidad de la persona desde la mente o ego hasta la totalidad del organismo como tal, se liberan los vastos potenciales del organismo total, poniéndolos a la disposición del individuo.

Todavía más profundas que estas terapias, se encuentran ciertas disciplinas, en general orientales, que apuntan al nivel de la 
conciencia de unidad. Estas disciplinas tienen la finalidad de curar la escisión entreel organismo total y el medio, y derevelar la identidad suprema con el universo entero (ver Wilber, 1988:26-27).

\section{NACIMIENTO DE LA CONCEPCIÓN HOLISTA INTEGRADORA}

Para entender mejor cómo se llega hasta este punto, Wilber puede darnos más claridad. Él profundiza en todos los tipos de demarcaciones que ha hecho el hombre desde su origen. Con el primer tipo de demarcación que establece, el ser humano traza una línea divisoria entre diferentes cosas y después las reconoce como constituyentes de un grupo o clase. Este primer tipo de límite forma la base de los siguientes. Entonces, según este autor, si el primer tipo de demarcación ${ }^{2}$ nos da una clase de cosas, el segundo nos da una clase de clases de cosas. Con los números, el hombre construyó un nuevo tipo de demarcación, más abstracta y más generalizada: una metademarcación. Y con eso el ser humano aumenta su capacidad de controlar el mundo natural por el hecho de que las demarcaciones llevan consigo poder político y tecnológico. Pero la contraparte de estos límites nuevos y más poderosos conlleva una enajenación y una fragmentación más profunda del ser humano y su mundo.

Así, esta nueva metademarcación -los números abstractos con sus actividades como contar, numerar, medir - según la observación de Wilber, introdujo desde los griegos, un sutil conflicto traducido en un dualismo, el cual se ha apoderado del mundo occidental hasta nuestros días: lo concreto frente a lo abstracto, lo ideal frente a lo real, lo universal frente a lo particular. Se ha manifestado como una "batalla entre lo racional y lo romántico, las ideas y las experiencias, el intelecto y el instinto, la ley y el caos, la mente y la materia" (Wilber, 1988:53).

Fue así que A ristóteles trazó demarcaciones, mientras que Kepler y Galileo trazaron metademarcaciones. Y todavía los científicos del siglo XVII dieron un paso más: "se les ocurrió imponer una demarcación

2 D emarcación como delimitación de cierto conjunto de cosas. 
a la metademarcación. Inventaron la metametademarcación, ${ }^{3}$ comúnmente conocida como ál gebra" (Wilber, 1988:54).

Wilber concluye que la primera demarcación produce una clase. La segunda (metademarcación) produce una clase de clases, a la que se llama número. La tercera demarcación (metametademarcación) produce una clase de clases de clases, a la que se llama variable. Esta metametademarcación trajo consigo nuevos conocimientos y, entonces, un aumento explosivo del poder tecnológico y político.

Estemismo autor señala que, en efecto, esta metametademarcación convierte las mediciones en conclusiones, los números en principios. Cada paso, cada nuevo límite, aporta un conocimiento más generalizado de las partes y sus relaciones, y por ende, más poder. Sin embargo, el precio es alto: conocer y controlar la natural eza por la demarcación, es separarse de ella. La prueba más grande es llegar la posibilidad de ser capaz de reducir a polvo la totalidad del planeta, incluido el ser humano mismo; hemos destruido una gran parte de la naturaleza, y la otra parte está agonizando por la contaminación del aire, de los océanos, de la tierra (Wilber, 1988:55).

Una pregunta importante que debe plantearse es, entonces: ¿Quién podía prever, después de tantos años de demarcaciones, que un nuevo viento revolucionaría la ciencia y superaría la física clásica con sus demarcaciones, metademarcaciones y metametademarcaciones? Y es posible afirmar que estas se desmoronaron frente a hombres como Einstein con su teoría de la relatividad, Schröedinger, Eddington, Louis de Broglie, Bohr y Heisenberg. Las fronteras y los mapas clásicos de la antigua física se vinieron abajo.

Sin embargo, a pesar del desarrollo de este nuevo paradigma, los pensamientos, ideas e intelecto de los individuos están todavía impregnados, o mejor dicho entrenados, en el modelo pasado. A los ojos de la física clásica, el universo aparecía como una colección de cosas y sucesos separados, cada uno aislado por demarcaciones definidas en el espacio y en el tiempo, susceptibles de ser medidas y

${ }^{3}$ Los términos metademarcación y metametademarcación nos dan la idea de la delimitación cada vez más concisa del conjunto de cosas. Cada vez se hace más pequeño o demarcado este conjunto. 
contadas con exactitud, aun las personas. Dicho proceso conducía finalmente a leyes y principios científicos que visualizan los objetos como entes separados. Wilber subraya que el átomo no se comportaba ya como una "cosa" separada, sino como algo nebuloso que se pierde infinitamente en su medio; no puede ser local izado, carece de demarcación, por lo que no puede ser medido. Así, los nuevos físicos cuánticos tuvieron que reconocer que las demarcaciones no eran reales sino el producto de la forma en que cartografiamos y acotamos la realidad. Consiguieron tener una percepción aguda del mundo real, del territorio sin fronteras, del mundo tal como es y no como lo clasificamos, delimitamos y cartografiamos. Wilber cita a Teilhard:

Considerada en su realidad concreta, la sustancia del universo no puede dividirse, sino que, como una especie de átomo gigantesco, forma en su totalidad la única realidad indivisible [...] Es imposible efectuar cortes en esta red, aislar una parte deella sin quelos bordes senos deshilachen y se nos enmarañen. (Teilhard deChardin, en Wilber, 1988:60)

En este aspecto, la ciencia moderna se acerca a la filosofía oriental, como lo han subrayado tanto el físico Fritjof Capra, como el paleontólogo P. Teilhard de Chardin:

La teoría de los cuantos ha abolido la noción de objetos fundamentalmente separados; ha introducido el concepto de participante para reemplazar al de observador y ha llegado a ver el universo como un entramado de relaciones recíprocas cuyas partes sólo se definen mediante sus conexiones con la totalidad. (Capra, en Wilber, 1988:61)

En opinión de Wilber, la razón por la cual en Oriente supieron todo eso mucho antes que la ciencia occidental, es porque los orientales no tomaron muy en serio las demarcaciones, "no se les subieron a la cabeza hasta el punto de que la cabeza y la naturaleza llegaran a andar cada una por su lado. Para Oriente, no hubo más que un camino, el Tao, el Dharma, que señalaba una unidad por 
debajo de las líneas divisorias de los mapas dibujados por el hombre" (Wilber, 1988:62).

Así, vemos que de acuerdo con algunos progresos más recientes de la ciencia moderna, y con la antigua sabiduría de Oriente, la realidad es lo que no tiene fronteras. Cualquier tipo de fronteras o de demarcación concebible es una simple abstracción a partir del complejo entramado del universo, y es por eso que todas las demarcaciones son mera ilusión, porque crean separación, -aun conflictos en donde no los hay-. "Revelar que la realidad es lo que no tiene fronteras es, pues, revelar que todos los conflictos son ilusorios" (Wilber, 1988:66).

\section{DEMARCACIÓN FICTICIA DE LA REALIDAD}

El ser humano pasa gran parte de su vida dibujando fronteras. Cada decisión que toma, cada acción y enunciación, están basadas en la construcción, consciente o inconsciente, de límites, de fronteras. Por ejemplo, tomar una decisión significa trazar una línea entre lo que se elige y lo que no. Desear algo significa dibujar una demarcación entre cosas placenteras y dolorosas, y es orientarse usualmente hacia las primeras. Sostener una idea significa esbozar una división entre los conceptos que uno considera verdaderos y los no verdaderos.

La mayoría de los problemas están creados por las divisiones y opuestos que se generan. Por ejemplo, cuanto más se aferra el ser humano al placer, más teme - necesariamente - al dolor. Cuanto más éxitos busca, mayor será el terror al fracaso. Cuanto más se aferra a la vida, más le asusta la muerte.

Es posible discernir que el hombre encara el problema del bien y del mal tratando de exterminar el mal, y enfrenta el problema de la vida y de la muerte intentando ocultar ésta bajo inmortalidades simbólicas. Del mismo modo, en filosofía, resuelve las oposiciones conceptuales ignorando uno de los polos. Por ejemplo, el material ista se empeña en reducir el espíritu a la materia, mientras el ideal ista se esfuerza por reducir la materia al espíritu. Esta meta de separar los opuestos y después aferrarse a las mitades positivas, parece ser una característica distintiva de la civilización occidental progresis- 
ta, tanto de su religión como de su ciencia, su medicina o su industria; el progreso, en última instancia, es simplemente avanzar hacia lo positivo y alejarse de lo negativo.

Sin embargo, para la mayoría es difícil creer que todos los opuestos son inseparables, y que cada uno sea el otro. Eso se debe a que se acepta como real la demarcación entre los opuestos. Si la realidad fundamental es una unidad de opuestos, entonces es posible decir que en esta realidad fundamental no hay fronteras.

Ken Wilber (1988) escribe que la dificultad de creer que los límites no existen, viene del hecho de que las fronteras tienen fascinados a los hombres, a tal punto que se ol vidan que las demarcaciones sólo se encuentran en la imaginación de los cartógrafos y nunca en el mundo real. Para él, una línea real se convierte en demarcación ilusoria cuando nos imaginamos que sus dos lados están separados y no tienen relación entre sí; esto es, cuando reconocemos la diferencia externa de los dos opuestos, pero ignoramos su unidad interna.

Para Wilber, el mundo real contiene líneas, pero no tiene fronteras; por ejemplo, la línea de la costa, donde agua y tierra se tocan, no es una mera separación, sino simplemente el lugar donde podemos visualizar claramente la diferencia entre uno y otro elemento; sin embargo, aun ahí, ambas se encuentran mezcladas. Percibimos entonces la inexistencia de la frontera como tal y la existencia de la línea física que separa unas cosas de otras, por ejemplo, los bordes de las hojas de los árboles o el contorno del cuerpo (Wilber, 1988:45).

En opinión de este mismo autor, el ser humano genera la ilusión de las demarcaciones no sólo por seguir las líneas de la naturaleza - línea de la costa, del horizonte, de la piel-, sino por trazar sus propias líneas mentales, tales como las ideas y conceptos. Con este proceso, aprende a distinguir, seleccionar, clasificar y reconocer la diferencia entre el exterior y el interior, sin embargo, tiende a olvidar la unidad implícita.

Pareciera importante plantear ahora una cuestión: ¿Cómo liberarnos de la costumbre de separar, de vivir problemas y conflictos absurdos, frutos de la guerra de los opuestos? Y asentar una posible respuesta: No se trata de separar los opuestos para lograr un progreso hacia lo positivo, sino más bien unificar y armonizarlos, tanto 
positivos como negativos, descubriendo un fundamento que trascienda y abarque a ambos. ¿Y qué es este fundamento? Es la conciencia de unidad misma. En esencia, como dicen todos los textos antiguos de sabiduría, así como también la física moderna: las cosas no son dos, sino una.

Como apoyo a esta afirmación, Wilber afirma que podemos decir que si la realidad no es dual, entonces no tiene fronteras. No se trata de detener los progresos en los diversos campos, sino de abandonar la ilusión de que la felicidad depende de ellos. Escribe Wilber:

Cuando se comprende que los opuestos son uno, escribe Wil ber, la discordia se disuelve en concordia, las batallas se convierten en danzas y los antiguos enemigos en amantes. Estamos entonces en condiciones de entablar amistad con la totalidad denuestro universo, en vez deseguir manteniéndolo dividido por la mitad. (Wilber, 1988:49)

\section{NUEVA PERCEPCIÓN: REALIDAD SIN FRONTERAS}

Hasta ahora, es posible concluir que las fronteras son producto de la realidad palpable. No existen fronteras naturales, sino que son una conceptualización que nos ayuda a fragmentar y captar la realidad; representan la forma en que la cartografiamos y la observamos. Confundir el territorio geográfico - sin fronteras naturales- con el mapa imaginario -con límites trazados- nos lleva a un trastorno profundo, nos transporta a la aparición de crisis mundiales -económicas, ecológicas, sociales - que tienen incidencia en la vida de la humanidad. Sencillamente, no hay fronteras en el universo.

Las separaciones que hemos creado en todas las cosas, aunque parecen tener sus raíces en la física clásica, las podemos encontrar en un nivel más profundo: el de nuestra conciencia. ${ }^{4}$ Las fronteras de ésta se borran paulatinamente con el paso de la evolución humana

${ }^{4}$ La conciencia aquí tiene un acepción diferente de la que conocemos, generalmente coloreada con una connotación moral; se trata del "darse cuenta", que en inglés se traduce como "awareness". Muchos autores modernos hablan del 
para llegar a la aprehensión del verdadero territorio sin demarcaciones que es la conciencia sin fronteras, de unidad, o según Teilhard, la superconciencia (Teilhard, 1967:103). Si la realidad es de hecho una condición en que no hay demarcaciones, entonces la conciencia de unidad es el estado natural en que ella reconoce esto.

Wilber comenta que el lenguaje humano no refleja esta realidad, por ser dualista. Las palabras, los símbolos y los pensamientos no son más que límites, porque cada vez que se piensa o se usa una palabra o un nombre, ya se están creando límites. Lo cierto es que la percepción de lo que no tiene fronteras es una percepción directa, inmediata y no verbal.

De igual manera, Wilber afirma que de todas las fronteras que el hombre construye, fortifica y defiende, la más fundamental -y a la que menos está dispuesto a renunciar - es la que establece entre lo que se es y lo que no; es precisamente la que crea una sensación de ser seres separados. Tan fundamental es esta demarcación primaria - la primera que se traza y la última que se borra - entreel yo quese es y lo ajeno a ese yo, que de ella dependen todas las otras demarcaciones que el ser humano establece (Wilber, 1988:67-68).

Este autor señala que estas fronteras que seguimos trazando son obviamente obstáculos a la conciencia de unidad o a la superconciencia. En este nivel de conciencia la percepción de que no hay límites es común, el sentimiento del yo se expande hasta incluir todo aquello que en el pasado se creyó ajeno a él. Y es cuando se entiende el carácter ilusorio de la demarcación primaria que el sentimiento de la propia identidad alcanza el Todo: "entonces no hay nada fuera de uno mismo, y, por ende, no hay dónde trazar ninguna especie de demarcación" (Wilber, 1988:69). Wilber subraya que saliendo entonces de la ilusión, el hombre se da cuenta de que no hay un "yo" separado, un "uno" aparte del mundo.

\footnotetext{
"despertar de la conciencia"; por ejemplo, Don Juan, en Carlos Castaneda habla de la capacidad de "ver" más allá de lo que vemos. Teilhard habla de un "despertar de nuestras conciencias a alguna superconciencia" (Teilhard, 1967: 103) que participa "en el despertar general de nuestras conciencias a la enorme y extrema organicidad de desarrollo" (Teilhard, 1967:352).
} 
Supone siempre que es algo aparte de la experiencia, pero al salir en busca de este algo, se desvanece en ella. Así, cuando se da cuenta de que no hay parte, cae dentro del Todo, y cuando comprende que no hay un "yo" separado (y que eso sucede en este mismo momento), entiende que "nuestra verdadera identidad es siempre la identidad suprema" (Wilber, 1988:78). Dicho de otro modo, sepercata de que el interior y el exterior, el sujeto y el objeto, el que ve y lo visto, son una misma cosa, de manera que, espontáneamente, ocurre el estado natural.

El ser humano se ha identificado con su cuerpo, su mente y su personalidad, creyendo que esos objetos constituyen su verdadero ser, y procura, a lo largo de la vida, defender, proteger y prolongar lo que no es más que una ilusión. "Somos las víctimas de un caso epidémico de identidad equivocada, mientras nuestra identidad suprema aguarda, con silenciosa certidumbre, que la descubramos" (Wilber, 1988:83). El mundo interior y el exterior no son más que dos nombres diferentes para el estado, único y omnipresente, de percepción de lo ilimitado. No se trata de que en la conciencia de unidad uno esté mirando el territorio real sin demarcaciones, sino más bien de que la conciencia de unidad "es" ese territorio.

Miguel Martínez, en su obra El paradigma emergente (1993), afirma que es de esperar que el nuevo paradigma emergente sea el que permita borrar la idea de la vida como una lucha competitiva por la existencia, salir de "la asfixia reduccionista y entrar en la lógica de una coherencia integral, sistémica y ecológica, es decir, entrar en una ciencia más universal e integradora, en una ciencia verdaderamente interdisciplinaria" (Martínez, 1993:20).

Las fronteras internas trazan la convivencia, hacen interactuar a unos con otros, delimitan las costumbres, la particular manera de ser y forman el inconsciente colectivo capaz de demostrar que, aunque distintos, más bien el hombre es producto de una cultura común: la de ser humanos. 
CONSTRUCCIÓN DE LA FRONTERA INTERNA DEL NORTE DE MÉXICO. HACIA UN ACERCAMIENTO SOCIAL

La frontera que separa a México y Estados Unidos - aparentemente, pues ya sabemos que son sólo delimitaciones humanas - tiene una construcción interna interesante. Las condiciones en las que se desarrollan las relaciones entre los habitantes de ambos lados de esta línea hace que existan complicadas redes que incluyen a ambas partes. En esto, existe una contradicción relevante: es visible que este muro de separación, incomunicación y aislamiento, atrae a un gran número de personas que giran a su al rededor: oficiales de migración y de las patrullas fronterizas, pero sobre todo, una creciente multitud de personas decidida e imposible de contener, que intenta cruzar. El movimiento de este flujo humano transforma la frontera en un lugar de alta comunicación, de encuentro de razas, culturas, familias, de intercambio, negocios, tráficos de todo tipo y relaciones humanas - a veces subterráneas, tales como el contrabando o el comercio desleal- como en ningún otro lugar en el mundo. La franja fronteriza de ambos lados de la línea divisoria ha llegado a ser una plaza pública en donde se tejen relaciones tan comunes como extrañas, tanto de ayuda incondicional a otros como de provecho personal o para grandes corporaciones.

Es interesante señalar que mientras las fronteras se endurecen en algunas partes del mundo, en otras tienden a desaparecer, como es el caso de la Unión Europea. Y es factible preguntar entonces: ¿Es esto un signo del cambio en nuestro tiempo?

A hora bien, los términos en los que está operando tal supresión pueden implicar inmensas y ricas enseñanzas, ya que se trata básicamente de desvalorizar ciertas funciones negativas en los límites de las naciones, al mismo tiempo que se pretende preservar la función esencial de identidad nacional, que permite el trazo de una frontera cultural.

Foucher (1988) se pregunta si las fronteras son necesarias y si deben quedarse como puntos de referencia esencial es. Cita a este propósito el discurso actual de los geopolíticos de la Comisión Europea: "Se trata de atacar resueltamente a esta especie de Europa feudal que 
no ofrece más que barreras, aduanas, formalidades y problemas burocráticos" (J. Delors, 1985, en Foucher, 1988:8). Este discurso encuentra eco favorable porque se sostiene en una apreciación común y corriente y habitualmente negativa de la frontera en general, que implica las connotaciones de barrera y constricción, arbitraria y artificial, colonial e imperialista.

Un hecho relativamente nuevo, subrayado por Foucher, es la aceleración de la hispanización del sur de Estados Unidos, que tiene por efecto el desplazamiento de la "frontera" de la América Latina hacia el norte - de Los Ángeles a San Antonio y Miami- a nivel lingüístico, cultural y demográfico. Al mismo tiempo, la frontera que diseña el área de atracción económica y cultural anglo-americana, sigue expandiéndose hacia el sur, América Central y el Caribe. "Asistimos en realidad, a la formación de una 'A mérica anglo-latina', que proviene de una intersección tan dinámica como crítica" (Foucher, 1988:136).

Los estudios demográficos estudiados por este autor, reportan estimaciones según las cuales habría de cinco millones a seis millones de ciudadanos estadounidenses de ascendencia mexicana, a los cuales se añaden de dos millones a tres millones de mexicanos residentes legales en Estados Unidos. Como lo hemos señalado, la gran mayoría de esta población vive en la frontera sur de este país. Ante esta marea humana, no se puede negar que las relaciones entre México y Estados Unidos escapen ampliamente a los dos aparatos de Estado, lo que explica su complejidad. La percepción estadounidense de las cuestiones de la frontera está, en primera instancia, dominada por los niveles locales de decisión y por el dogma de la libre empresa (Foucher, 1988:137).

Se puede ver entonces, como parte de la población vecinal de la frontera, que lo cotidiano en las ciudades gemelas es la intendencia, la contaminación del agua y del medio ambiente, la repartición de las aguas de irrigación, la evacuación de la basura y de las aguas negras, el desarrollo de las economías locales y los tráficos y violencias de toda especie: una infinidad de lazos que se tejen entre las dos sociedades civiles, las dos economías, las dos culturas - si esto se puede decir, porque el predominio de la cultura 
mexicana o hispánica es muy fuerte-, para dar cabida a una nueva comunidad formada por gente de ambos lados de la frontera. Michel Foucher (1988:384) dice que ambas culturas formarán el esbozo de una mexamérica, de la cual ya existen señales, como por ejemplo, el spanglish, que es la fusión del inglés y el español o la importación del taco en las cadenas de fast food. A este respecto, Alan Riding escribe:

Desde que las leyes y actitudes más liberales al norte de la frontera, hicieron que los divorcios "al vapor" ya no fueran negocio y se cerraran muchas zonas rojas en México, han tratado de atraer a los turistas que buscaban una comidad mexicana, una artesanía barata, o simplementeun viaje de un día en otro país. (Riding, 1985:344)

Es cotidiano observar como habitantes de la frontera, que en estos lugares reina al go único en el mundo: un intenso tejido de relaciones administradas cotidianamente de manera descentralizada: los gobernadores colaboran de manera permanente, así como también los presidentes municipales y los funcionarios de todos los servicios. La suerte de cada uno de los dos lados está recíprocamente ligada. Por ejemplo, una devaluación del peso favorecerá a las maquiladoras, sin embargo, reducirá el poder de compra y el consumo de los mexicanos, clientes de los servicios y comercios del "otro lado".

En la frontera, los mexicanos y los estadunidenses, analiza Riding, "han aprendido a vivir lado a lado, perciben los intereses locales como algo compatible en muchos sentidos y resienten, abiertamente, la interferencia de la ciudad de México o la de Washington en su interdependencia natural" (Riding, 1985:384).

Se reconoce en general, y lo subraya Foucher, que los "latinos" de origen mexicano generalmente no renuncian a su cultura ni a su idioma, sino que más bien buscan imponer una educación bilingüe, por el contrario de los inmigrantes asiáticos o de origen europeo quienes, a la segunda generación, eligen cambiar de nombre y no hablar más que el idioma anglo-americano. Además, los "latinos" no buscan una asimilación de la cultura "anglo", no quieren romper 
con sus raíces latinas, ni con la lengua y la religión, y tampoco al parecer, con su visión del mundo (Foucher, 1988:386).

Son entonces este tipo de actividades las que demuestran la existencia de fronteras internas que hacen desaparecer las demarcaciones externas. Son estas líneas las que permiten a unos convivir con los demás y elaborar un tejido de relaciones humanas que ayudan a mantener la condición de seres sociales y comunitarios.

\section{CONCLUSIONES}

... U no sabe que la frontera es como la orilla del mar, que no es agua ni arena. Que es una relación móvil, una forma de ver, una realidad humana que puede

recrearse...

Sólo es la mirada radical, donadora de valor y respeto la que puede llegar a superar dramas históricos de siglos

Antonio Paoli

A un cuando se ha establecido que la percepción humana construye la frontera bajo dos tipologías - las fronteras externas en la concepción mecanicista y las fronteras internas en la corriente holista-, es importante resaltar, como primera conclusión, que éstos no son enfoques contradictorios, sino que se complementan, sobre todo bajo la consideración de la propuesta holista.

Por otra parte, el hecho de hablar de frontera nos lleva entonces a dos connotaciones fundamentales: la primera, como frontera externa, física, capaz de separar de la manera más abrupta y sutil a dos países o dos objetos que se construyen con el fin de la protección o el dominio contra de los otros que - supuestamente- quieren lanzarse a la conquista. La segunda connotación se refiere a la frontera interna, aquélla que existe dentro del ser humano y que le impide su desarrollo amplio e integral como tal. Las fronteras internas se constituyen con el fin de separar y delimitar lo que el ser humano es de lo que no, de saber hasta dónde llegan los límites de su potencial. En tanto que las fronteras externas se constituyen a partir del enfoque mecanicista y cartesiano que rige la ciencia desde hace tres siglos. 
La manera de percibir los elementos que conforman dichas fronteras condicionan al hombre a tener miedo y a sentir la tajante separación entre dos cosas que son presuntamente diferentes.

Uno de los ejemplos más Ilamativos entre las fronteras externas es la frontera que separa a los Estados Unidos de toda A mérica Latina. Simboliza la separación de lo que no es divisible, empezando por el nivel orográfico. Y sellega a la conclusión de que el hecho de confundir el territorio - sin fronteras palpables - con el mapa - lleno de fronteras imaginarias - , lleva a un trastorno profundo, capaz de crear crisis sociales tan fuertes como las que existen hoy en día.

Un nuevo enfoque científico, cuyos albores se ven en los inicios del siglo XX, nos habla de la unión e interdependencia de todas las cosas que conforman nuestra realidad palpable. Esta nueva visión fue dada, en los inicios, por la física cuántica, ciencia que permeó a las demás en su nueva manera de ver y comprender el ambiente.

Los físicos cuánticos - quienes marcan la pauta del nuevo paradigma - tuvieron que reconocer que las demarcaciones no eran reales sino el producto de la forma en que cartografiamos y acotamos la realidad. En esta visión innovadora, las fronteras, más que líneas limítrofes entre las naciones, continentes y océanos, se vuelven lugares de intercambios existenciales y culturales en donde se tejen las relaciones de intenso apoyo mutuo. La característica más importante de la teoría cuántica es que el observador humano no sólo es necesario para observar las propiedades de un objeto, sino que es imprescindible, incluso para definir tales propiedades. La universal conexión recíproca de la naturaleza incluye siempre y de manera esencial al observador humano y a su conciencia. En física atómica, por ejemplo, jamás se puede hablar de la naturaleza sin hablar al mismo tiempo desí mismo. A sí lo formuló el científico W. Heisenberg: "La ciencia natural no se limita a describir y explicar la naturaleza; es parte de la acción recíproca entre la naturaleza y nosotros" (Heisenberg, 1963:75). En física moderna, pues, el científico no puede desempeñar el papel de un observador desapegado, sino que se va comprometiendo en el mundo que observa.

John Wheeler (1974) considera que el compromiso del observador es la caraterística más importante de la teoría cuántica, razón por la 
cual sugirió que la palabra observador fuera reemplazada por participante. ¿Y quién no es observador, quién no es investigador, quién no es participante, por el sólo hecho de ser un ser humano?

Si en física clásica, con el modelo mecanicista era posible, o al menos aceptable, separar al sujeto del objeto, en física moderna, el observador y lo observado no pueden ya considerarse como separables, porque el observador llega a formar parte de la constitución del objeto observado. Por esto, el humano es actor más bien que espectador.

Es posible tomar el ejemplo de la psicología, y más concretamente del psicoanálisis; se hizo la observación a Freud que también el psicoanalista tenía un inconsciente, y por lo tanto, al analizar el inconsciente de un paciente, podría ser víctima del suyo propio.

Al observar la frontera de la manera descrita en este ensayo, quizá ahora se entienda mejor la complejidad de su sentido. Más de lo que se cree, todos participamos en la construcción de las fronteras como separación o barreras que fragmentan, pero también en su creación como flujo de relaciones o interacciones complementarias. La visión interna del ser humano guía su visión externa. Como seres humanos, proyectamos lo que creemos y lo creamos. Realmente somos co-creadores del mundo que habitamos, estableciendo obstáculos o desplazándolos, inventando trabas o desvaneciéndolas, cultivando rencores y corajes o transformándolos en relaciones de cooperación y mutuo entendimiento.

Lasfronteras, entonces, pueden ser - según deseo y decisión individual - una serie de acontecimientos desconcertantes y degradantes; un lugar de persecución; un muro divisorio infernal; o transformarse en una plaza de fiesta, de encuentros de los opuestos, de descubrimientos de las riquezas recíprocas, de intercambios de presentes, de flujo y tejido de relaciones. Depende de cada uno de nosotros y de nosotros como total idad. Existe fuera lo que se ha fomentado dentro; no hay división. El hombre proyecta externamente tanto sus fronteras o divisiones internas como su belleza y armonía interior. Ése es el reto: construir un mundo donde los seres humanos comprendan que en la medida que limiten su desarrollo integral, la capacidad para relacionarse y ganar terreno pacífico con otros va decreciendo. 
El punto central de esta imagen de un nuevo ser humano se concentra en la posibilidad que se tiene de saber que no existen límites como tales y que el desenvolvimiento renovado va en pos de un ser interconectado con todo lo que él es y con lo que le rodea.

La frontera se presenta entonces como una posibilidad dual, cuando es pensada como muro divisorio o tejido de relaciones. Finalmente, hay que reconocer que es una decisión individual la manera de concebirla y tratarla. Hoy, la oportunidad de cambiar la constante división que se produce por la demarcación de fronteras - distintas razas, religiones, cosmovisiones- está en el poder y la creatividad interna de cada ser humano.

\section{BIBLIOGRAFÍA}

Bohm, David. 1988. La totalidad y el orden implicado. 1a. ed., Barcelona, Kairós.

Brooks, David y Jim Cason. 1994. “Una comisión nombrada por el Capitolio presenta plan de 9 puntos". La jornada, 30 de Septiembre, México, D.F.

Capra, Fritjof. 1998. El punto crucial. Ciencia, sociedad y cultura naciente. Argentina, Estaciones.

Church, J. George. 1989. “Freedom!". Time, EUA.

Fernández, Raúl A. 1980. La frontera M éxico-Estados U nidos, U n estudio socio-económico. México, Terra Nova.

Foucher, Michel. 1988. Fronts et Frontières. Un tour du monde géopolitique. 1a. ed., Fayard.

García Montoya, Celina. 1994. “Tomarán huella a 'ilegales' y agre gan 100 agentes al SIN". La crónica, 1 de octubre, M exicali, Baja California, México.

1994. "Devuelven a 'mojados' por Mexicali”. La crónica, 2 de octubre, Mexicali, Baja California, México.

Garibay, Aurelio. 1994. "Aumenta el patrullaje fronterizo al comenzar la 'Operación Portero'”. La jornada, 30 de septiembre, Mexicali, Baja California, México. 
Guerrero Chiprés, Salvador. 1994. "Sólo por Tijuana, hasta 720 mil cruces ilegales a EU cada año". La jornada, 26 de Septiembre, México, D.F.

Heisenberg, W. 1963. Physics and Philosophy. Londres, Allen \&Unwin. Kuhn, Thomas. 1971. La estructura de las revoluciones científicas, México, Fondo de Cultura Económica.

Le Gloannec, Anne-Marie. 1990. “El muro de papel". N exos, 146, febrero, México, D.F.

Martínez Miguelez, Miguel. 1993. El paradigma emergente. Barcelona, Gedisa.

Riding, Alan. 1985. Vecinos distantes. México, D.F., Joaquín Mortiz; Planeta.

Teilhard de Chardin, Pierre. 1967b. El porvenir del hombre. 4a. ed., Madrid, Taurus.

Walsh, Roger y Vaughan, Frances. 1987. M ás allá del ego. 3ra. ed., Barcelona, Kairós.

Wheeler, J.A. 1974. "The Universe as Home for Man”. A merican Scientist, núm.62, EUA.

Wilber, Ken. 1988. La conciencia sin fronteras. 1a. ed. Mexicana, México, Kairós-Colofón, S.A. 